\title{
An Electron Microscopic and Radioautographic Study of the Rat Parotid Gland after Actinomycin D Administration '
}

\author{
SEONG S. HAN \\ Departments of Oral Biology and Anatomy, The University of Michigan \\ School of Dentistry and Medical School, Ann Arbor, Michigan
}

\begin{abstract}
Rat parotid glands have been examined by electron microscopy and radioautography $\left(\mathrm{H}_{3}\right.$-leucine incorporation) at various intervals following an injection of actinomycin D in the amount of $0.125 \mu \mathrm{g}$ per gram of body weight. Light microscopic observations confirmed results from previous experiments similar to this. Radioautographs showed a definite drop in number of silver grains in acinar cells of the parotid from experimental animals. This was most pronounced in 7-day rats which received $\mathrm{H}_{3}$-leucine four hours prior to sacrifice. Electron microscopic observations revealed a generalized reduction in number and degree of the organization of organelles concerned with protein synthesis. Furthermore, frequent appearances of lipid droplets, cytolysomes and crystalloid structures were noted. Changes of the nucleolus included the reduction of its size and the formation of spherical encapsulated bodies. A brief discussion is made of these results in relation to the biochemical nature of actinomycin effects on protein producing cells.
\end{abstract}

During the past several years numerous biochemical and radioautographic workers have taken advantage of the unique effect of actinomycin D on RNA and protein biosyntheses. Results from these studies show that most, if not all, of the cytoplasmic RNA is derived from the nucleus and that the administration of actinomycin D brings forth a substantial reduction of protein and total inhibition of RNA syntheses (Tamaoki and Mueller, '62; Caspersson et al., '63; Franklin, '63; Levy, '63; and Merits, '63), although there has been some conjecture regarding the resistance of four sRNA synthesis (Franklin, '63). The degradation of ribosomes by actinomycin D has been observed both under in vivo (Staehelin et al., '63) and in vitro conditions (Wiesner et al., '65).

Insofar as the structural reflection of these chemical effects is concerned, remarkable nuclear and nucleolar changes following the administration of the antibiotic in a massive dose have attracted the attention of several electron microscopists (Journey and Goldstein, '61; Goldstein et al., '60; Schoefl, '64; and Jezequel and Bernhard, '64). Few described any modification of cytoplasmic structures in those studies dealing with the acute effect.
On the other hand, serious alterations in histological and cytochemical characteristics of rat salivary glands have been observed following a sublethal dose of the actinomycin D (Jhee and Han, '64; and Jhee, Han and Avery, '65). The cytological changes observed in the salivary gland cells include: an early nuclear pycnosis and decrease in number of nucleoli, loss of the cytoplasmic basophilia, and vacuolization and rarification of the cytoplasm. The aim of the present communication is to describe the fine structural changes of the rat parotid gland following a sublethal dose injection of actinomycin D. A limited number of light micrographs and radioautographs which illustrate the picture of $\mathrm{H}_{3}$-leucine incorporation will be presented for the purpose of orientation and correlation.

\section{MATERIAL AND METHODS}

Adult male Sprague-Dawley rats were paired according to weight and one of each pair was injected with $0.125 \mu \mathrm{g}$ actinomycin $D / g$ body weight. Three pairs as a group were sacrificed on days $1,3,5,7$, 10,14 and 21 after the injection. One pair

1 This study was supported in part by grants from U.S.P.H.S. (DE-1620) and from American Cancer Society (IN-40-F). 
of these were intracardially injected with $\mathrm{H}_{3}$-leucine in the amount of $2.5 \mu \mathrm{c} / \mathrm{g}$ body weight ten minutes prior to sacrifice, whereas the remaining two pairs were given the same injection 30 minutes and four hours before the sacrifice respectively.

Under ether anesthesia small pieces of the parotid gland were dissected out by iridectomy scissors and fixed either in $2 \%$ $\mathrm{OsO}_{4}$ in $\mathrm{M} / 10$ phosphate buffer at $\mathrm{pH} 7.4$ or in $2 \%$ glutaraldehyde followed by $\mathrm{OsO}_{4}$ post-fixation. The tissues were dehydrated, embedded in Epon in a routine manner, sectioned on a LKB ultramicrotome and studied in a Hitachi HU-11 electron microscope.

For radioautography, pieces of the parotid gland were fixed in Bouin's solution, double-embedded in parlodion and paraffin, sectioned at $6 \mu$, coated with Kodak NTB-3 liquid nuclear track emulsion and kept in an air-tight slide box containing Drierite stored at $4^{\circ} \mathrm{C}$. After 4 to 6 weeks of exposure the slides were developed in Dolmi, stained with hematoxylin and eosin, and observed under a Zeiss photomicroscope.

\section{OBSERVATIONS}

\section{Histologic and radioautographic appearance}

The microscopic appearance of parotid cells confirmed data from previous studies. In control animals, acinar cells were well defined containing a distinct basophilic region at the base and a supernuclear accumulation of zymogen granules. The nucleus was large, rounded and vesicular in appearance having one or more prominent nucleoli (fig. 1). One day after the administration of actinomycin $\mathrm{D}$, the pycnosis of acinar nuclei became apparent. By day 3, many acinar cells had condensed pycnotic nuclei with an apparent reduction of the cytoplasmic basophilia (fig. 2). By the end of the first week, the nuclear pycnosis has progressed further and occasional vacuoles were seen in association with the nucleus (fig. 3). The cytoplasm of the cell became less dense and gave the impression of a generalized rarification. By day 10, nuclei started to return to normalcy assuming a rounded contour with the reappearance of nucleoli and by day 14 many acinar cells showed a fair amount of the basal basophilia (fig. 4).

In addition radioautographic slides showed the following results. Ten minutes and 30 minutes after injection of $\mathrm{H}_{3^{-}}$ leucine, silver grains were more or less diffusely distributed throughout the gland cell both in control and experimental animals, although in the former group more silver grains appeared to be concentrated in the basal and supernuclear Golgi region of the cell after 30 minutes of $\mathrm{H}_{3}$-leucine injection. By four hours after injection the number of grains in experimental animals were reduced in number and they were distributed evenly throughout the entire cell (fig. 5). This was most obvious in the day 7 animal. In contrast to this, cells from control glands after four hours of $\mathrm{H}_{3}$-leucine injection showed a definite concentration of silver grains in the apical cytoplasm which corresponded to the area of zymogen accumulation (fig. 6).

\section{Electron microscopy}

Acinar cells. For the convenience of description most of the micrographs to be presented will be from rats sacrificed seven days after actinomycin $D$. As has been shown by previous workers, acinar cells from control animals contained numerous profiles of regularly arranged rough-surfaced endoplasmic reticulum (RER) which were basally located and occasional mitochondria being interposed between membranes of the RER (figs. 7, 9). Supernuclearly, a large Golgi complex was located. The Golgi complex was made up of 4 or 5 units, each one of which was composed of several stacks of flattened membranes and a large number of small vesicles and a few vacuoles. Elsewhere the apical cytoplasm was filled with zymogen granules. Under conditions of the fixation zymogen granules had a somewhat homogeneous, finely granular interior of moderate electron density and the surrounding membrane often showed irregularities and possible breakages. Only occasional granules showed the bizonal appearance, i.e. a darker outer zone with a lighter interior.

In comparison to this, cells from experimental animals were usually smaller, containing fewer profiles of the RER in the basal region (fig. 8). Despite the reduction 
in total number of ribosomes in experimental animals, a fair amount of polysomes were seen, whenever the RER was oriented in a favorable plane. The Golgi apparatus was definitely reduced in its degree of organization and only 1 or 2 units of stacked membranes were visualized in any single cell at a given plane of section. Individual units of the Golgi complex were small and were devoid of or drastically reduced in number of the vesicles (fig. 10). Many zymogen granules gained peripheral density showing the bizonal appearance, while others have lost the clarity of the outer limiting membrane (fig. 8).

In certain cells zymogen granules formed aggregates of various sizes by fusion of several to a dozen or more granules (fig. 11). Although the preservation of membranes surrounding the circumference of such aggregates was questionable in osmium fixed preparations, clear-cut limiting membranes were observed following glutaraldehyde fixation. Occasionally the aggregates contained other cytoplasmic organelles such as ribosomes, RER, mitochondria and what appeared to be lipid droplets. In many instances, the zymogen granules contained within the aggregate body maintained its own limiting membranes. They were similar in appearance to typical cytolysomes which primarily contained mitochondria and degraded products of the RER, and increased in number towards the end of the first week (fig. 12). A number of lipid droplets appeared at this time especially in the basal region of cells, some of them in close proximity to the nuclear membrane (fig. 14). Large crystalloid structures were often present in acinar cells.

Modifications of nuclear structures induced by actinomycin $\mathrm{D}$ in the parotid acini were of the following two types. First, there was a remarkable reduction in size of the nucleolus which appeared to have lost most, if not all, of the $150 \AA$ unit granules associated with the structure (figs. $15,16)$. The second change was the formation of small encapsulated areas of nucleoli (figs. 17, 18, 19, 20). It appeared that a finely filamentous substance developed around pieces of degenerating nucleoli which would eventually surround and separate that portion of the nucleolus from the rest of the nucleoplasm forming a spherical body as judged by observations on a large number of sections. Such encapsulated bodies contained the ribosomelike granules as well as dense homogeneous portion of the nucleolus.

Ducts. Essentially no alterations were observed in the structure of intercalated duct cells which appeared to maintain a normal complement of the RER, ribosomes, a small Golgi apparatus and mitochondria. No significant change was observed in the intercellular relationship.

Some of the cells making up the secretory duct, however, showed the following differences (figs. 21, 22, 23). The appearance of mitochondria, basal infoldings of the plasma membrane and intercellular interdigitations was largely unchanged, although mitochondria often became smaller and denser than those of control animals (fig. 13). More significantly, small vacuoles of irregular shape which characterized the apical cytoplasm of secretory duct cells were increased in number (figs. $22,23)$. They were also larger, many of them showing an irregular stellate contour and contained a fairly electron dense matrix.

\section{DISCUSSION}

The light microscopic observation made in conjunction with radioautographic studies confirms results obtained from previous works (Jhee and Han, '64) and provides for further support that actinomycin $D$ does induce serious morphological defects in cells of the parotid gland which produce proteinaceous enzymes. Furthermore, the differences in appearance of grain distribution observed in radioautographs of day 7 rat especially after four hours of $\mathrm{H}_{3}$-leucine injection indicates a definite damage done to the synthetic machinery responsible for $\mathrm{H}_{3}$-leucine incorporation. The elegant work by Warshawsky et al. ('63) has also shown that at four hours $\mathbf{H}_{3}$-leucine accumulates maximally in the zymogen region of pancreatic acinar cells which are not unlike parotid gland cells, although our recent observation indicates that pancreatic cells show more discreet pattern of $\mathrm{H}_{3}$-leucine distribution than parotid cells (Han, '66). 
The electron microscopic observation of cells taken from the same tissue as used for radioautography provides a definite support for the conclusion derived from radioautographic data. Thus, all intracellular structures identified so far to be parts of the synthetic apparatus for proteins showed serious reduction in degree of the organization or in their number. In addition the appearance of other structures that have been observed in situations of altered glandular metabolism, such as the formation of crystalloids or fat droplets, add to the evidence that the physiology of the acinar cells is definitely altered. Of interest is to note the persistence of polysomes in insulted cells which might be related to the smaller dose employed in this study. However, it is also possible that they represent more resistant polysomes as implied by previous biochemical studies (Staehelin, '63) which showed only 50 to $80 \%$ breakdown of polysomes even after a massive amount of actinomycin capable of total inhibition of RNA synthesis.

It is difficult to assess, although highly desirable, exactly what is the primary morphological effect of any insult on the cell. In electron microscopy, the difficulty is doubled because of problems related to differentiating and quantitating changes. Based on what has been known from biochemical studies, one might arbitrarily define the primary structural effect of actinomycin $D$ to be changes in the nucleolar structure and number of ribosomes, whereas alterations of the membrane system of the ER, Golgi apparatus and number of zymogen granules might be taken as necessary consequences of reduced secretory function. The formation of cytolysomes, lipid droplets and crystalloids, might be regarded as further adaptive changes related to abrupt imbalance of various intermediary metabolic processes which might also come after other types of physiologic insults. For instance, the formation of lipid droplets in fibroblast cells from scorbutic guinea pigs were related to reduced synthesis of collagen in healing wounds (Ross and Benditt, '62) and the increase in cytolysomes has been related to various aspects of reduced or upset cellular functions (Novikoff, '63). The formation of crystalloids similar to what has been observed in this study was observed by Scott and Pease ('64) in parotid acinar cells, although they found them in relation to a heightened functional status.

Nucleolar alterations observed in this study are somewhat different from the acute effect of actinomycin D observed in pancreatic acinar cells (Jezequel and Bernhard, '64) and cultured kidney cells (Schoefl, '64) and from the chronic effect on the fibroblast of the dental pulp (Han et al., '66). Rather than showing the segregation of nucleolar components, nucleoli in experimental animals in our hands showed a drastic reduction in number of ribosome-like granules and might be of significance in view of the role nucleoli play in RNA metabolism (Perry et al., '61). The formation of encapsulated bodies within the nucleus has been occasionally observed in some of the lymphoid cells as well as in duct cells of salivary glands (Han, '66), although none of these previously noticed intranuclear bodies contained what could be identified as materials originating from the nucleolar structure; namely, the ribosome-like granules and the homogeneous dense substance of the nucleolus.

The real significance of the phenomenon of nucleolar encapsulation remains to be elucidated. It is tempting, however, to speculate on the following possibilities on purely logical grounds: It might represent a means by which the cell might preserve a vital intranuclear organelle concerned with RNA metabolism during a period of time when RNA synthesis is severely restricted; or alternately it might be an expression of the final stage of nucleolar deterioration which may result in the extrusion of the encapsulated matters into the cytoplasm. The latter possibility is particularly intriguing, since the nuclear extrusion has been observed in other types of cells (Bak, '66). Furthermore, the extrusion might be a mandatory affair, if the content of encapsulated bodies were degraded masses destined to be hydrolyzed by lysosomal enzymes which, so far as known, are exclusively cytoplasmic.

The lack of effect on intercalated duct cells indicates the limitedness of the role that duct cells might play in protein bio- 
synthesis of the organ. On the other hand, cells in the secretory duct apparently show accumulation of apical vacuoles with an increase in electron density of their content and, if one were to presume that dense vacuoles or granules might represent secretory product by the cell, the observation could be regarded as expressing a possible retention of secretory products as the result of hypofunctioning of duct cells. In fact a similar situation was observed following fasting and atropin administration, conditions which are known to suppress duct functions (Scott and Pease, '64).

\section{LITERATURE CITED}

Bak, I. J. 1966 The ultrastructure of the substantia nigra and candate nucleus and the cellular localization of catechol amines. Exp. Brain Res., in press.

Caspersson, T., S. Farver, G. E. Foley and D. Killander 1963 Cytochemical observations on the nucleolus-ribosome system. Effect of actinomycin D and nitrogen mustard. Exp. Cell Res., 32: 529-552.

Franklin, R. M. 1963 The inhibition of ribonucleic acid synthesis in mammalian cells by actinomycin D. Biochem. Biophys. Acta, 72: 555-565.

Goldstein, M. N., I. J. Slotnick and L. J. Journey 1960 In vitro studies with HeLa cell lines sensitive and resistant to actinomycin. Ann. N. Y. Acad. Sci., 89: 474-483.

Han, S. S. 1966 Unpublished observations.

Han, S. S., J. K. Avery and J. S. Bang 1967 The effect of actinomycin $D$ on the fibroblast of the incisor pulp of the rat, a study by quantitative radioautography and electron microscopy. Arch. Oral Biol., in press.

Jezequel, A. M., and W. Bernhard 1964 Modifications ultrastrurales du pancreas exocrine de rat sous l'effet de l'actinomycine D. J. Microscopie, 3: 279-296.
Jhee, H. T., and S. S. Han 1964 Effects of actinomycin $\mathrm{D}$ on the salivary glands of the rat. Life Sci., 3: 1239-1247.

Jhee, H. T., S. S. Han and J. K. Avery 1965 A study of salivary glands of rats injected with actinomycin D. Am. J. Anat., 116: 631-652.

Journey, L. J., and M. N. Goldstein 1961 Electron microscope studies on HeLa cell lines sensitive and resistant to actinomycin D. Cancer Res., 21; 929-932.

Levy, H. B. 1963 Effect of actinomycin D on HeLa cell nuclear RNA metabolism. Proc. Soc. Exp. Biol. Med., 113: 886-889.

Novikoff, A. B. 1963 Lysosomes in the physiology and pathology of cells: contribution of staining methods. In: Lysosomes, Ciba Foundation Symposium, pp. 36-73.

Perry, R. P., A. Hell and M. Errera 1961 The role of nucleolus in ribonucleic acid and protein synthesis. Biochim. Biophys. Acta, 49: 47.

Ross, R., and E. P. Benditt 1962 Wound healing and collagen formation. II. Fine structure in experimental scurvy. J. Cell Biol., 12: 533551.

Schoefl, G, E. 1964 The effect of actinomycin $D$ on the fine structure of the nucleolus. J. Ultrastr. Res., 10: 224-243.

Scott, B. L., and D. C. Pease 1964 Electron microscopy of induced changes in the salivary gland of the rat. In: Salivary Glands and Their Secretions, Internat'l Ser. Monogr. Oral Biol., ed. by L. M. Sreebny and L. Meyer, Macmillan, N. Y., pp. 13-43.

Staehelin, T., F. O. Wettstein and H. Noll 1963 Breakdown of rat liver ergosomes in vivo after actinomycin inhibition of messenger RNA synthesis. Science, 140: 180-183.

Tamaoki, T., and G. E. Mueller 1962 Synthesis of nuclear and cytoplasmic RNA of HeLa cells and the effect of actinomycin D. Biophys. Biochem. Res. Comm., 9: 451-454.

Warshawsky, H., C. P. Leblond and B. Droz 1963 Synthesis and migration of proteins in the cells of the exocrine pancreas as revealed by specific activity determination from radioautographs. J. Cell Biol., 16: 1-21.

Wiesner, R., G. Acs, E. Reich and A. Shafig 1965 Degradation of ribonucleic acid in mouse fibroblasts treated with actinomycin. J. Cell Biol., 27: $47-52$. 
PLATE 1

EXPLANATION OF FIGURES

1 A portion of the parotid gland from a control animal. Notice welldefined large cells with distinct basal basophilia and large nucleus containing prominent nucleoli. Approximately $\times 840$. Fixed in Bouin's solution, and stained with hematoxylin and eosin.

2 A portion of the parotid gland of a rat injected with actinomycin $D$ three days prior to sacrifice. The pycnosis of acinar nuclei is evident in most cells and the cytoplasm appears rarified with a loss of the basophilia. Approximately $\times 840$. Fixed in Bouin's solution, and stained with hematoxylin and eosin.

3 A portion of the parotid gland from a rat injected with actinomycin $D$ seven days prior to sacrifice. Further degeneration is noted in the cytoplasm, including the formation of vacuoles which often are associated with nucleus. Approximately $\times 840$. Fixed in Bouin's solution, and stained with hematoxylin and eosin.

4 A portion of the parotid from a rat injected with actinomycin $D$ 14 days prior to sacrifice. Note the restoration of the nucleolar structure as well as the recovery of basophilic materials in the cytoplasm. 

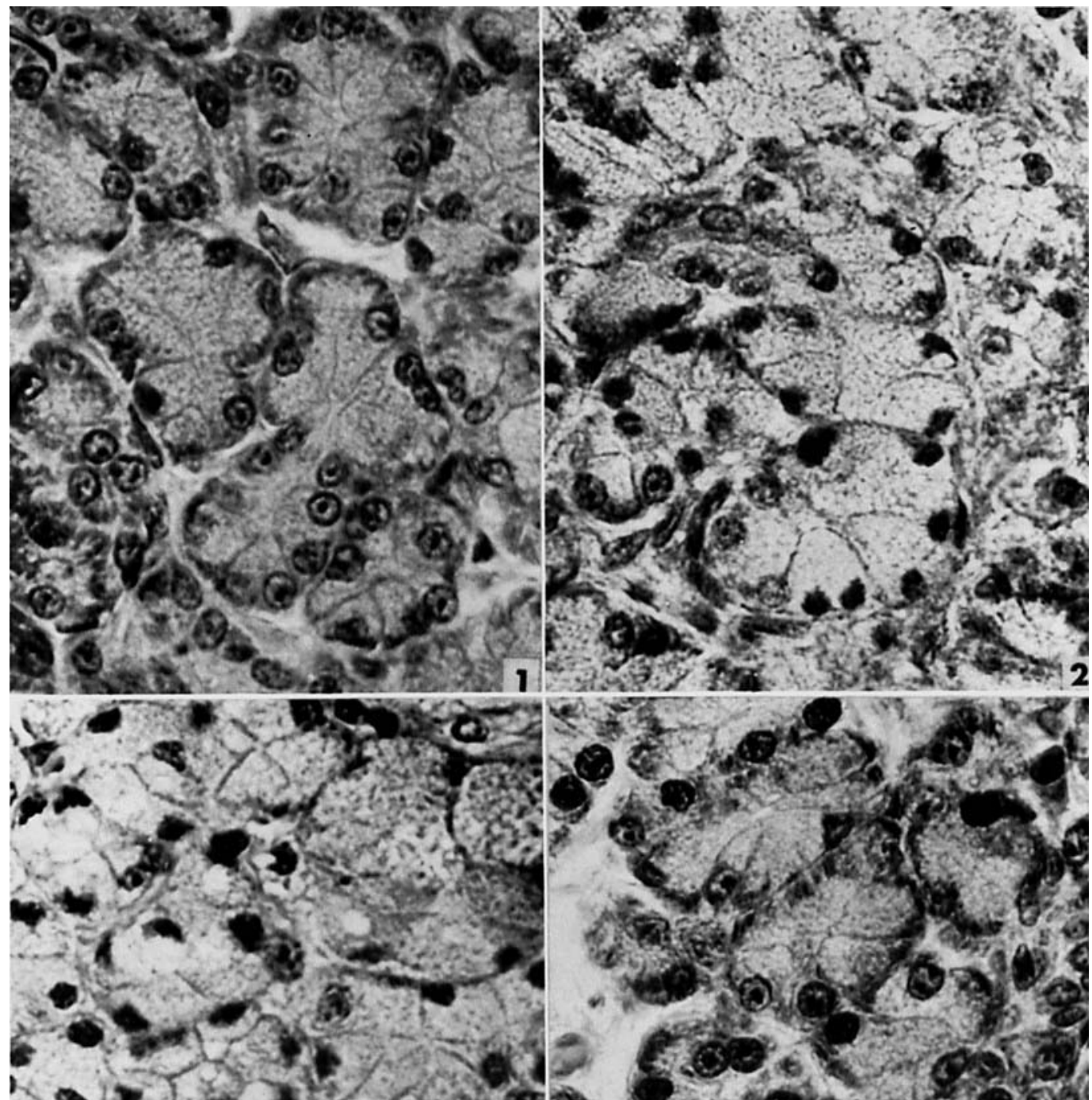

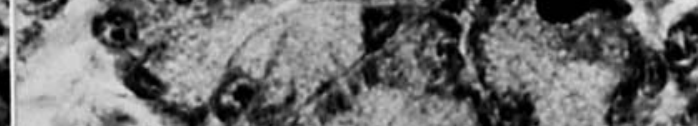

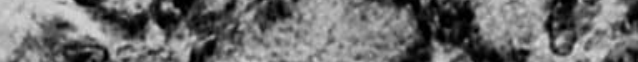

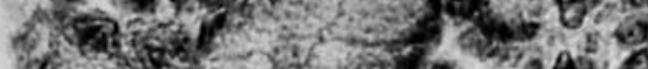
by

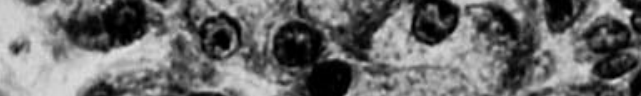

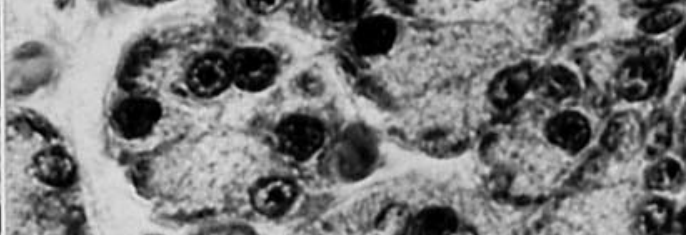
\&. A. Wf

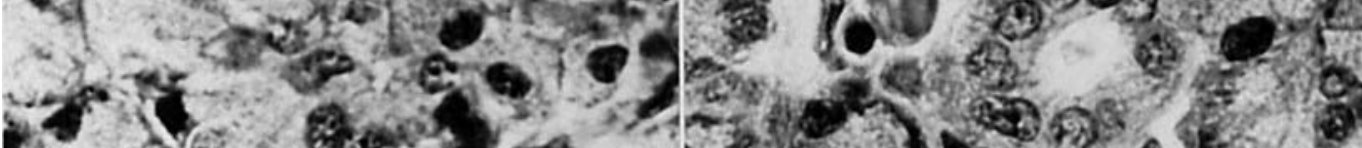

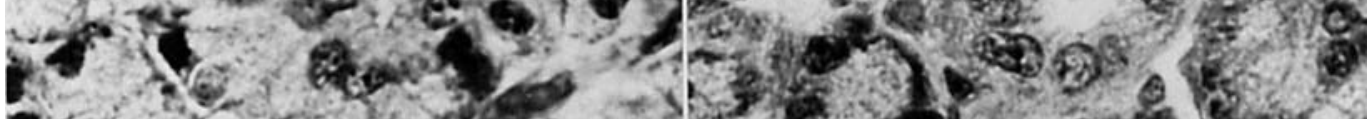

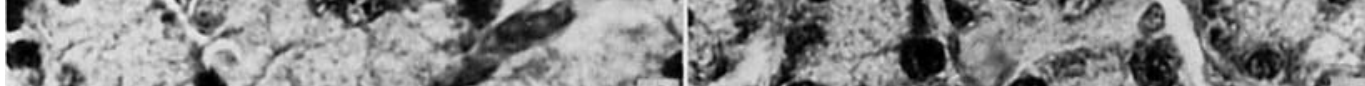

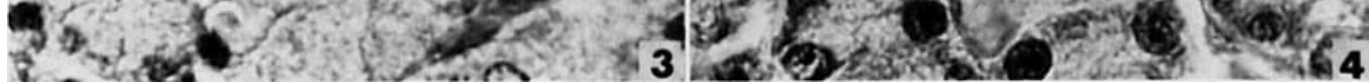




\section{PLATE 2}

EXPLANATION OF FIGURES

5 A radioautograph of the parotid from a 7-day experimental animal, which was given an injection of $\mathrm{H}_{3}$-leucine four hours prior to sacrifice. The cytoplasmic degeneration depicted in preceding photographs is evident. Silver grains are distributed throughout the glandular tissue without any preferential pattern of localization. Approximately $\times$ 920. Fixed in Bouin's solution, and stained with hematoxylin and eosin after development of the radioautograph.

6 A radioautograph of the parotid from a 7-day control rat, which was given $\mathrm{H}_{3}$-leucine injection four hours prior to sacrifice. The silver grains are predominantly located in the supernuclear region where the accumulation of zymogen granules occurs. Approximately $\times 920$. Fixed in Bouin's solution, and stained with hematoxylin and eosin after development of the radioautograph. 

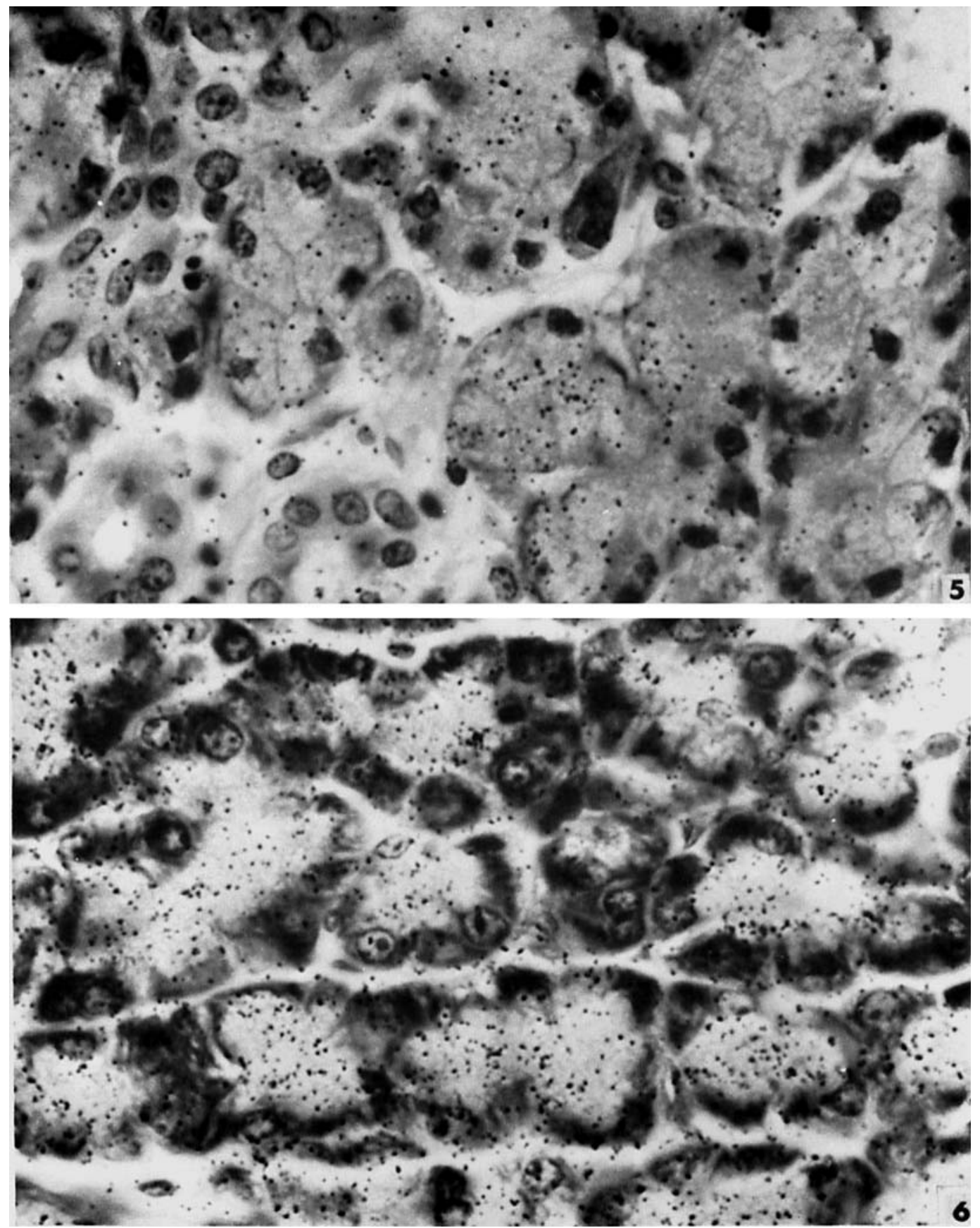
PLATE 3

EXPLANATION OF FIGURES

7 A low power electron micrograph of an acinar cell of the parotid gland from the 7-day control rat. The basal portion of the cytoplasm is packed with a well-developed RER and numerous ribosomes, whereas the supernuclear portion contains several well-organized Golgi units and numerous zymogen granules. $\mathrm{OsO}_{4}$ fixation. Approximately $\times 8,600$.

8 A low power electron micrograph of an acinar cell of the parotid gland of a 7-day experimental rat. Notice the reduction in organization of the RER at the base of the cell. Only a few units of the Golgi apparatus are visible and many of the zymogen granules show the bizonal appearance. $\mathrm{OsO}_{4}$ fixation. Approximately $\times 9.400$. 


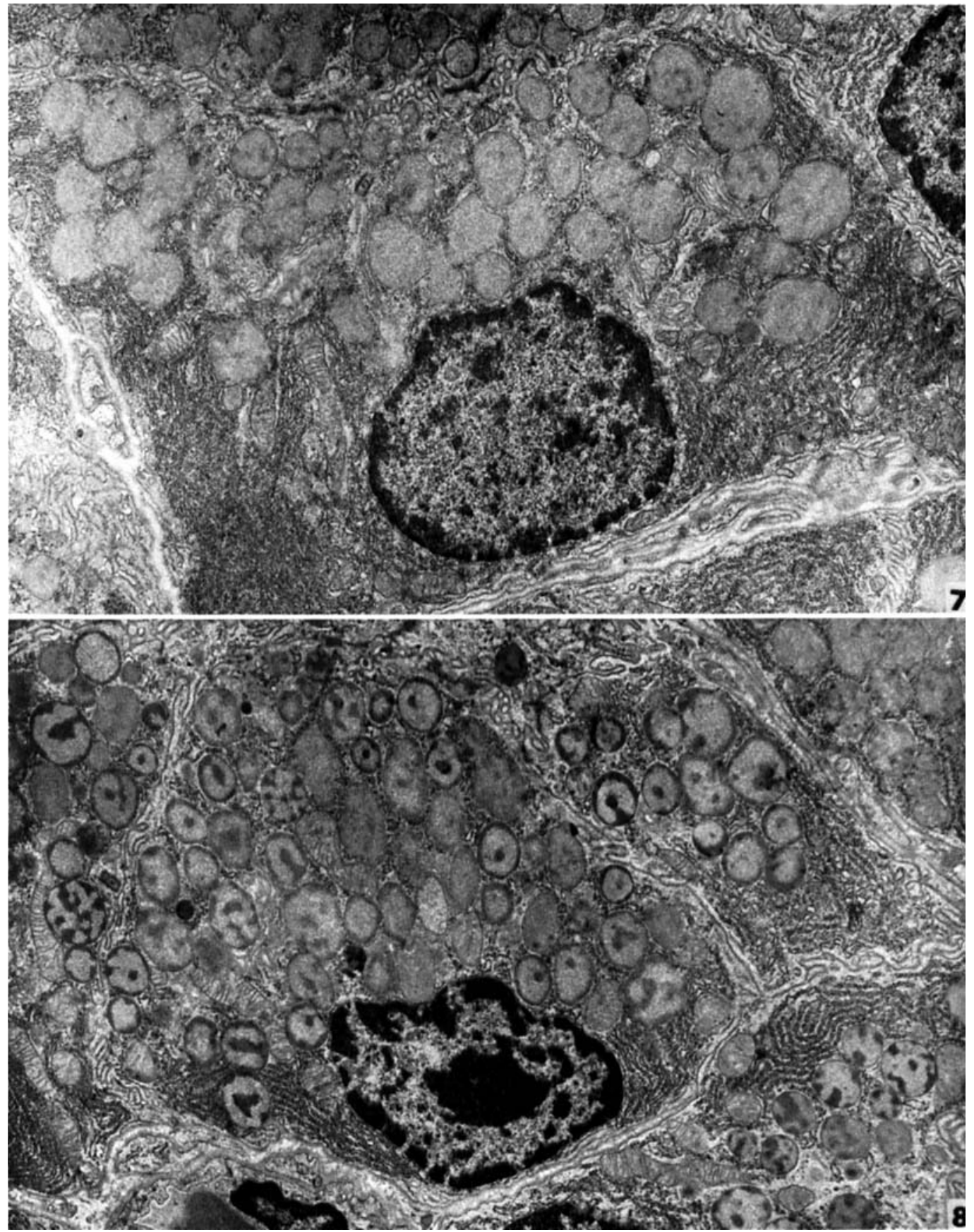


PLATE 4

EXPLANATION OF FIGURES

9 One of several units of the Golgi apparatus of an acinar cell of the parotid gland from a control rat. Notice the extensiveness of membranous elements and numerous small vesicles associated with them. $\mathrm{OsO}_{4}$ fixation. Approximately $\times 14,000$.

10 A profile of the Golgi apparatus of an acinar cell of the parotid gland from an experimental animal. Compared to figure 9 , this unit is smaller and the number of associated vesicles is much fewer. $\mathrm{OsO}_{4}$ fixation. Approximately $\times 18,600$. 


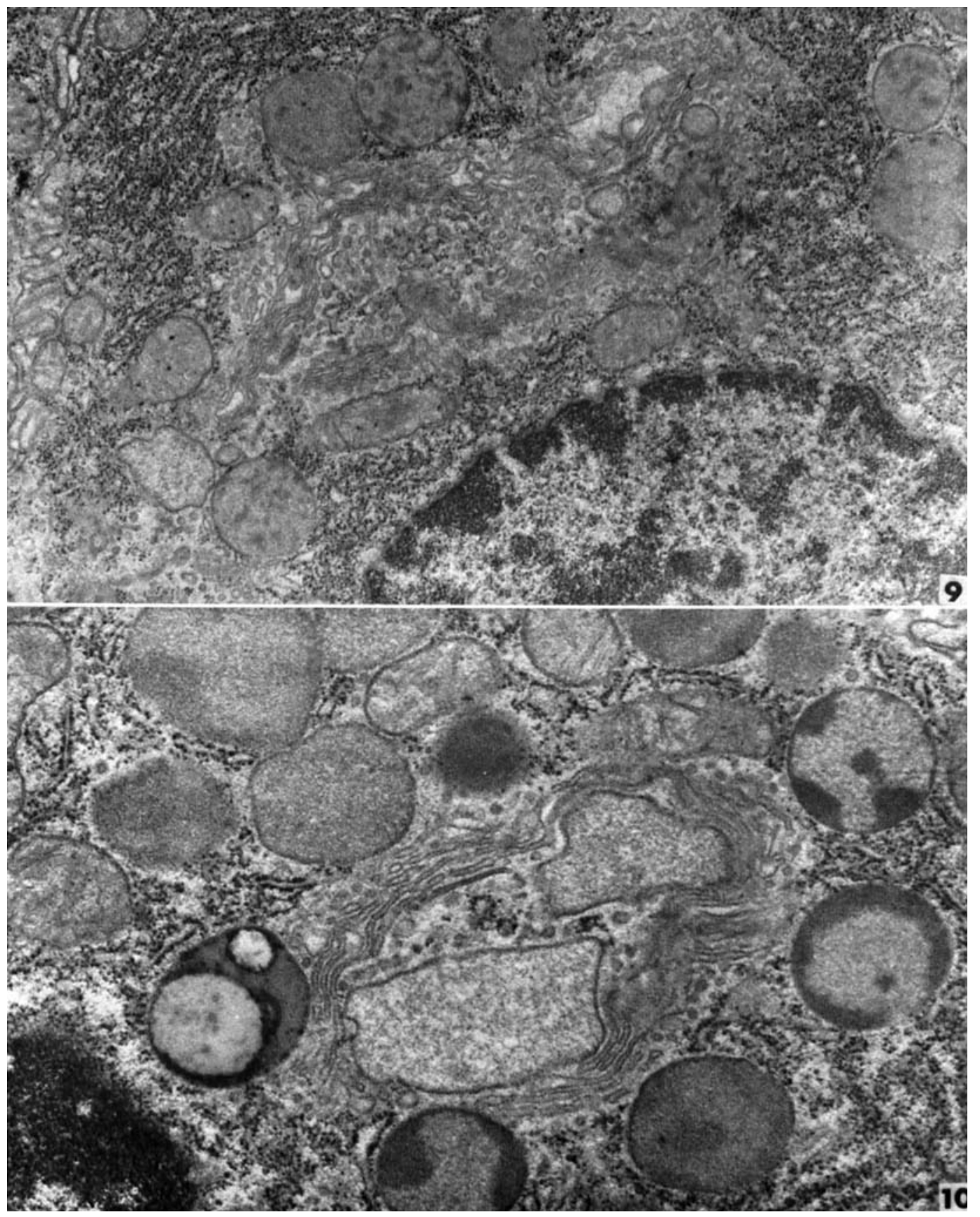




\section{PLATE 5}

EXPLANATION OF FIGURES

11 The appearance of aggregated zymogen granules in parotid acinar cells from an experimental rat, fixed in glutaraldehyde. Notice the presence of ribosomes, the RER, mitochondria and many zymogen granules. The outer limiting membrane of such aggregates as well as that of zymogen granules appears to be intact. Approximately $\times 18,000$.

12 A portion of an acinar cell of the parotid gland from an experimental animal, demonstrating a small cytolysome which contains a degenerating mitochondrion and ribosomes. $\mathrm{O}_{5} \mathrm{O}_{4}$ fixation. Approximately $\times 32,600$.

13 A portion of a secretory duct cell of the parotid gland from an experimental rat. Notice the rounded appearance of mitochondria, one of which seems to have become condensed but showing distorted cristae and an intact intramitochondrial granule. $\mathrm{OsO}_{4}$ fixation. Approximately $\times 28,400$.

14 Portions of acinar cells of the parotid gland from an experimental animal. Notice the formation of lipid droplets in the cytoplasm, many of which are located in association with the somewhat irregular nuclear membrane. $\mathrm{OsO}_{4}$ fixation. Approximately $\times 9,200$. 

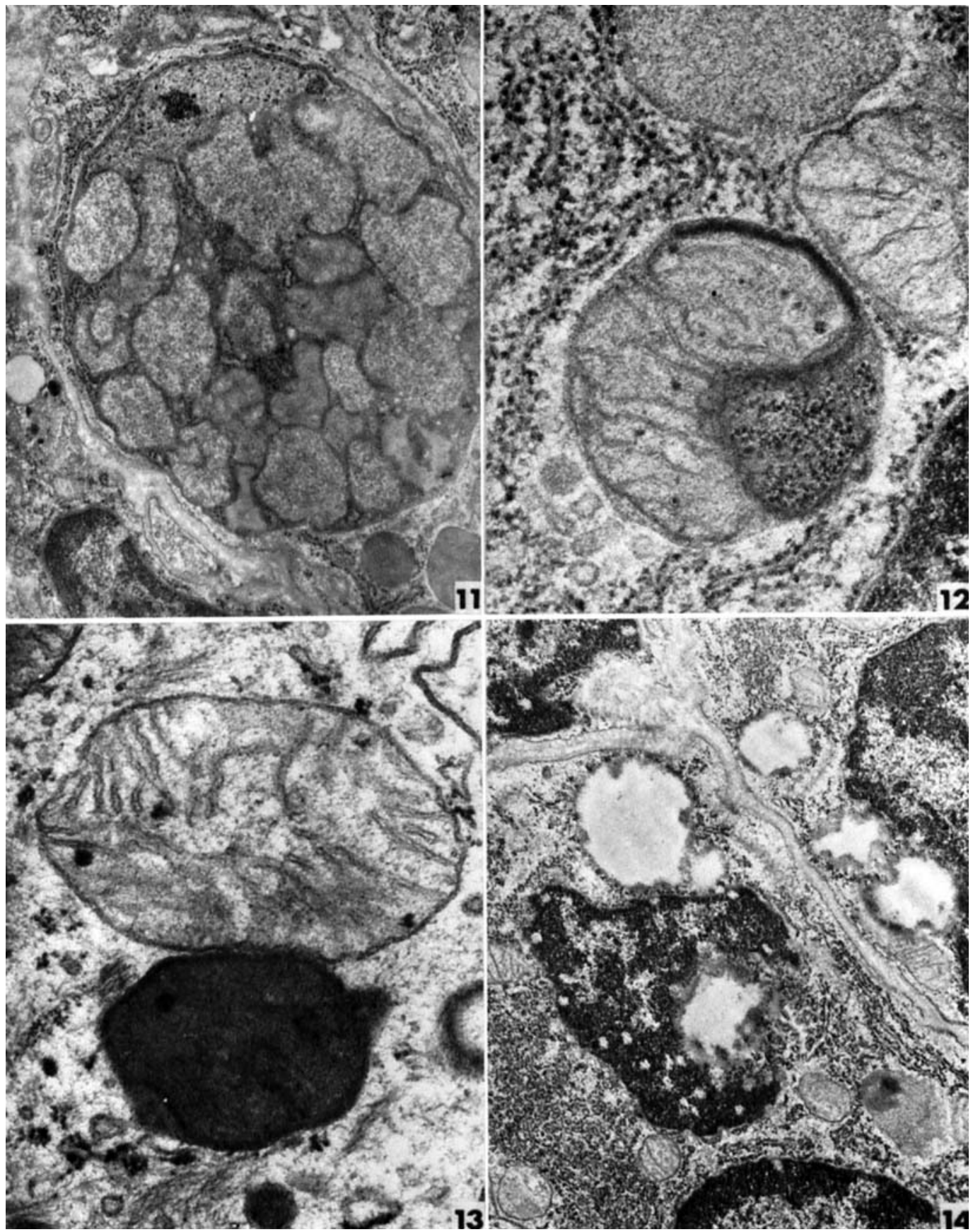
PLATE 6

\section{EXPLANATION OF FIGURES}

15 A nucleolus of an acinar cell of the parotid from a control animal. Notice the large size of this nucleolus which shows an impressive accumulation of ribosome-like granules associated with it. $\mathrm{OsO}_{4}$ fixation. Approximately $\times 98,800$.

16 A nucleolus of an acinar cell of the parotid from an experimental animal. The size of the nucleolus is smaller than the one shown above and it is practically denuded of the ribososome-like granules. $\mathrm{OsO}_{4}$ fixation. Approximately $\times 102,000$. 

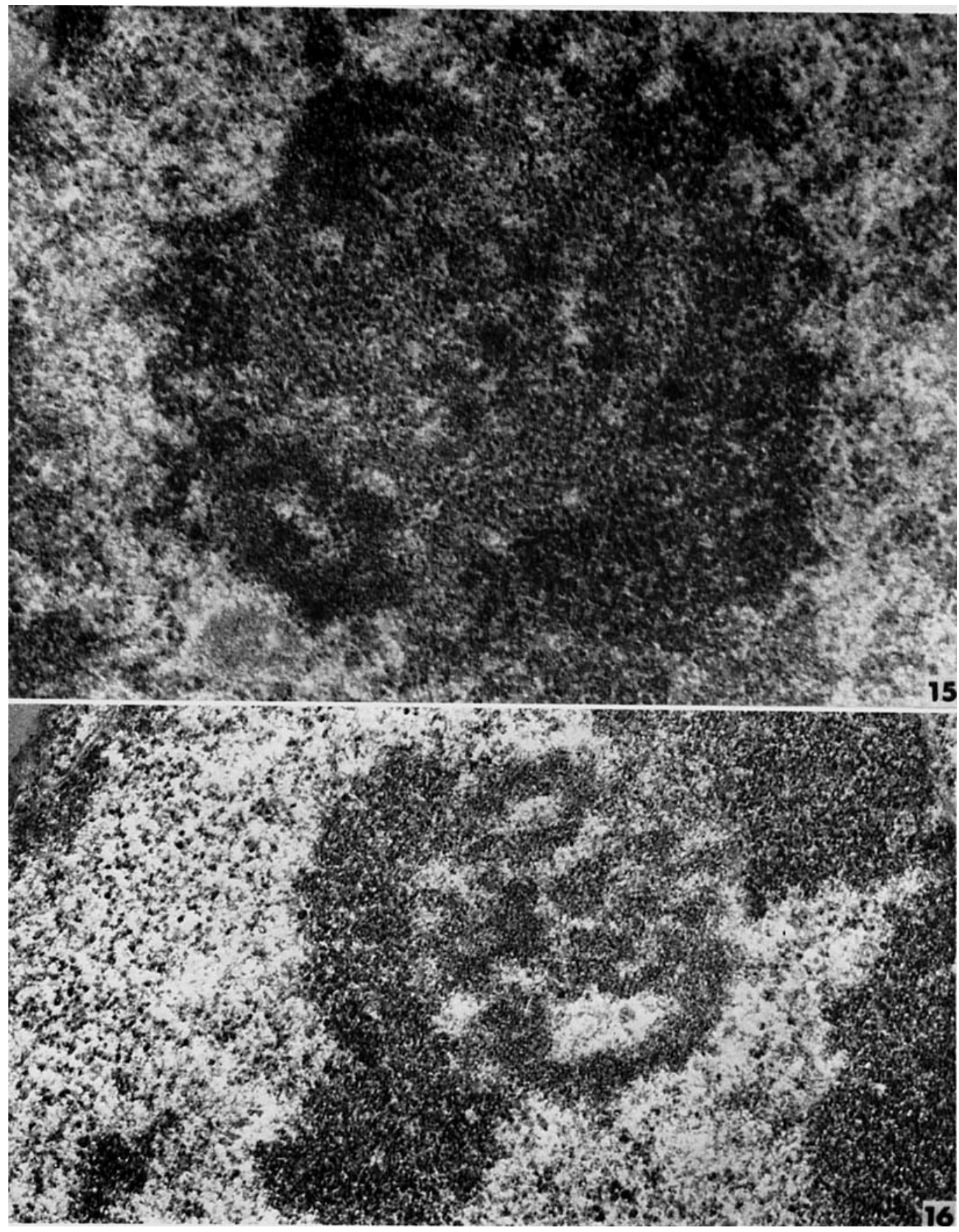
PLATE 7

EXPLANATION OF FIGURES

17-20 The formation of encapsulated nucleolar bodies. Note the appearance of the finely fibrillar structure surrounding a portion of the already small nucleolus in figure 21. The structure on figure 22 suggests that the fibrillar material has almost surrounded the small piece of nucleolar substances. Figures 23 and 24 show profiles of encapsulated bodies as found most frequently. The spherical bodies appear to contain a fair amount of ribosome-like granules as well as the homogeneously dense nucleolar structure. $\mathrm{OsO}_{4}$ fixation. Approximately $\times 88,400$. 


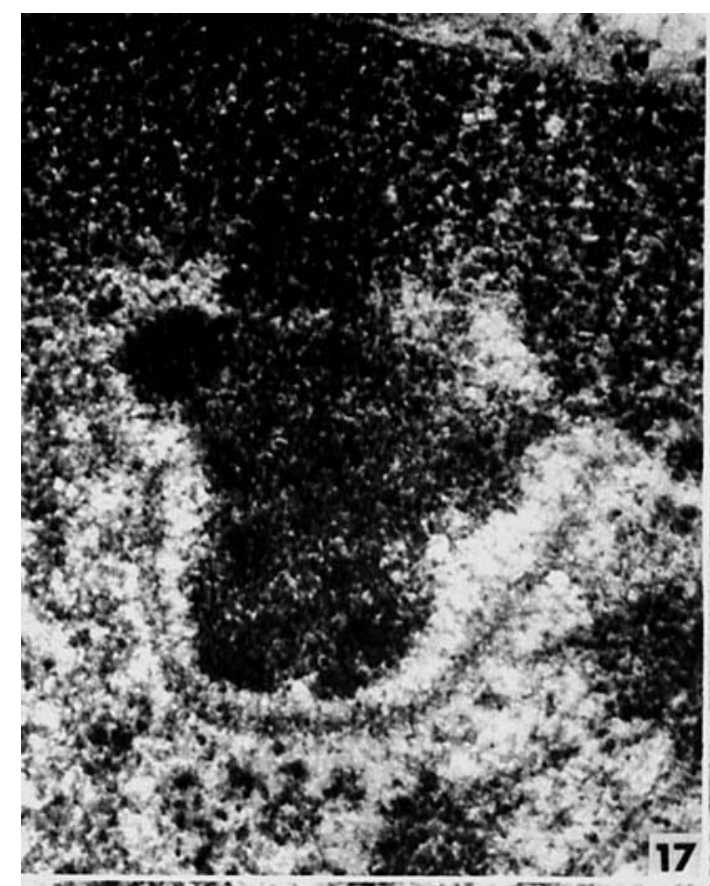

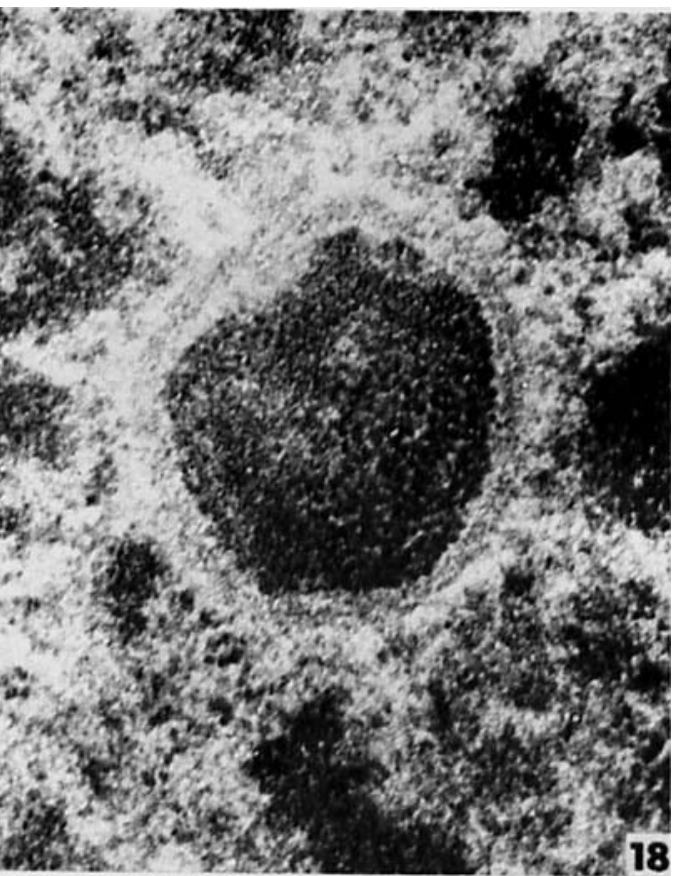

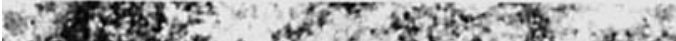

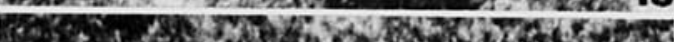

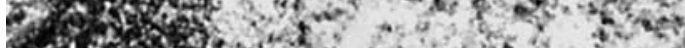

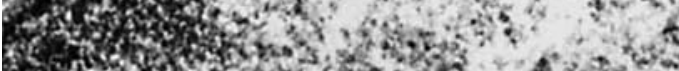
$190 \mathrm{~s}$ -

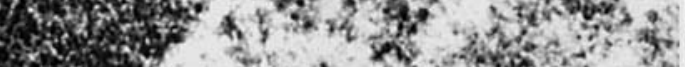

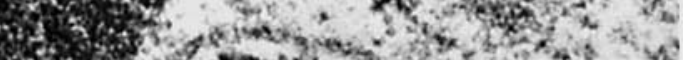

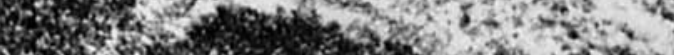

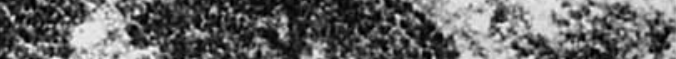

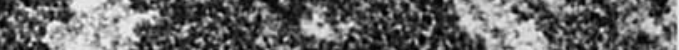

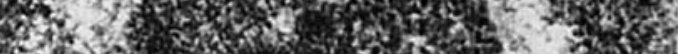

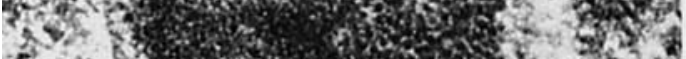
Pal

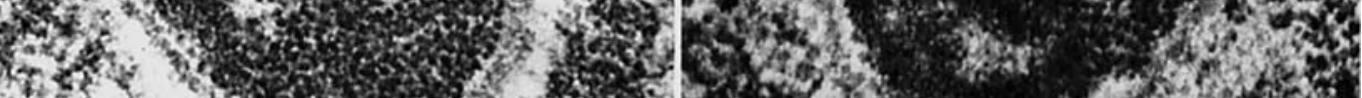

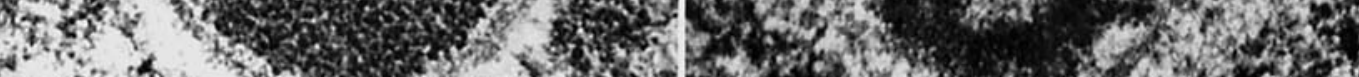

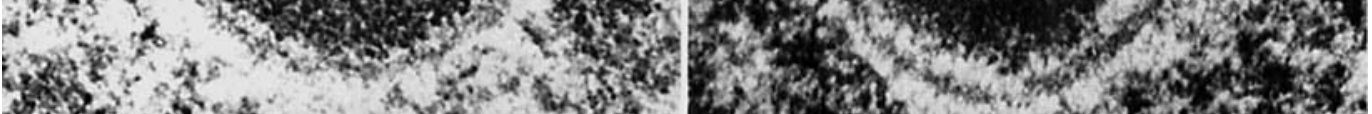

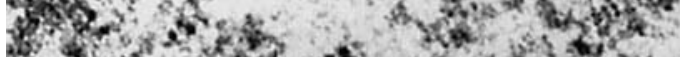

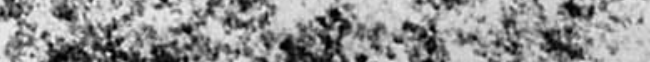

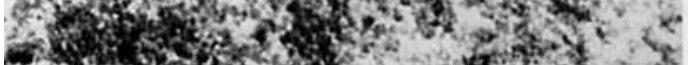

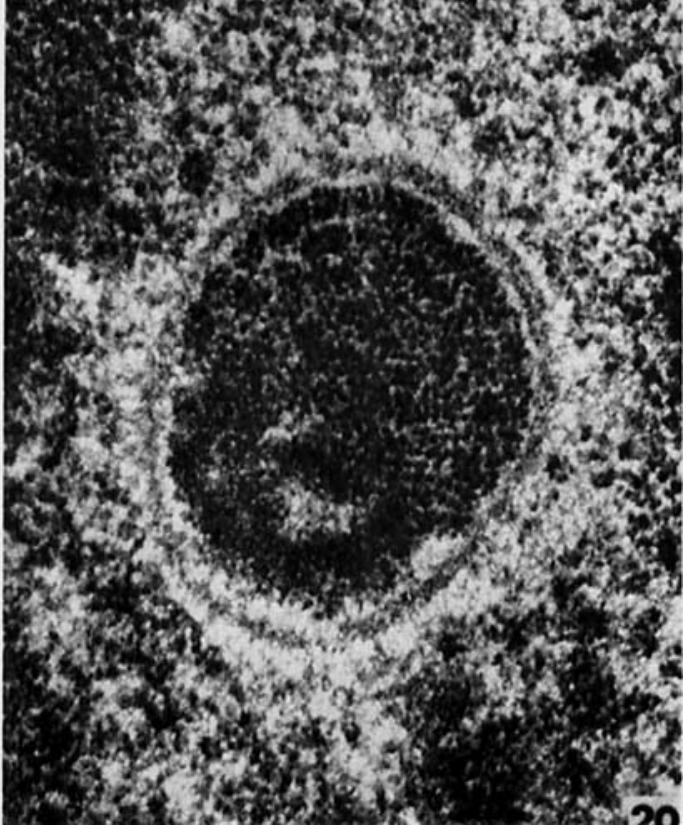

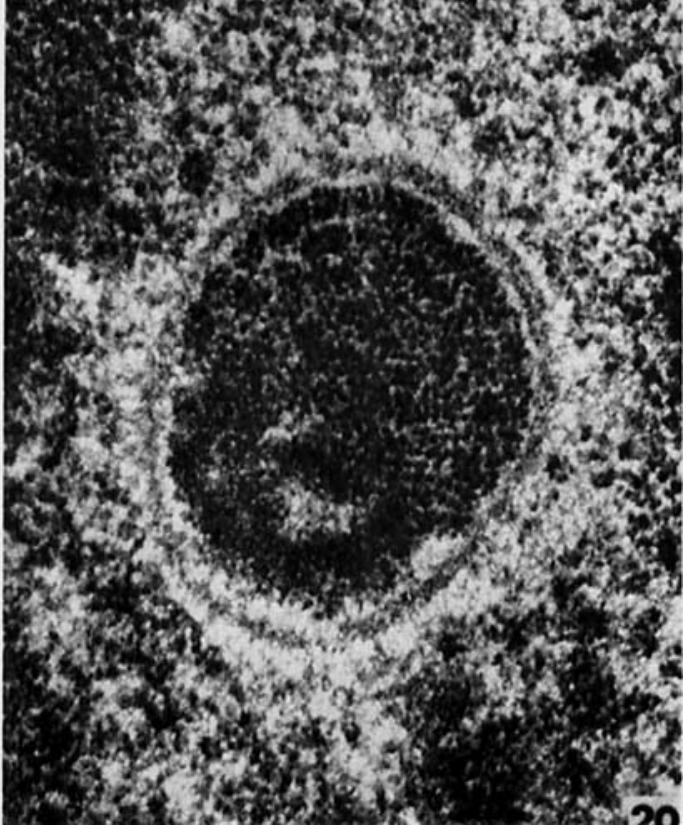

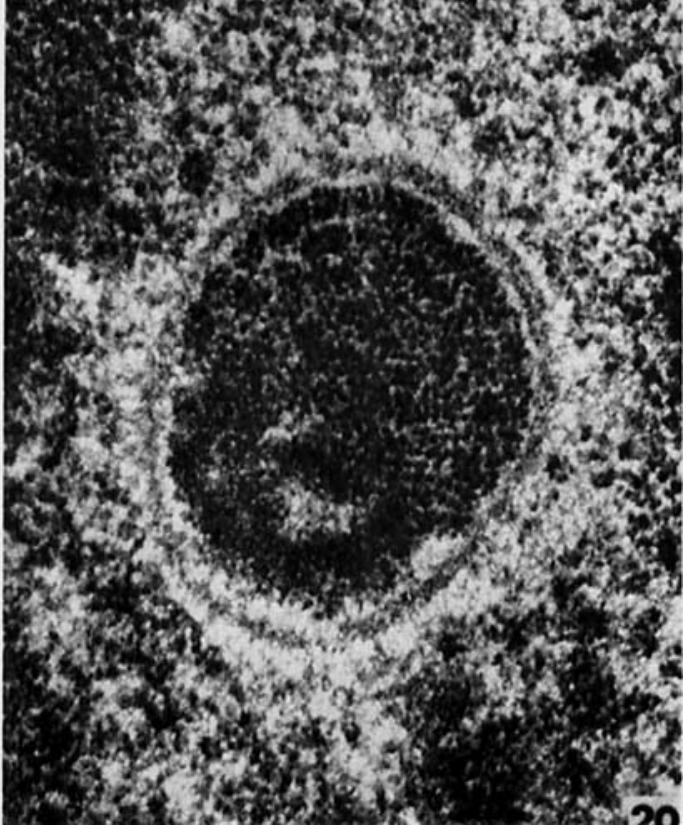

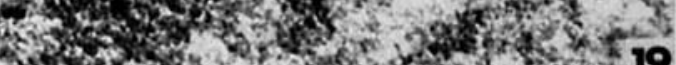


PLATE 8

EXPLANATION OF FIGURE

21 A portion of a secretory duct of the parotid gland from a control rat. The tall cell body contains a large number of basally located mitochondria in association with the infolded plasma membrane. A limited number of apical vacuoles may be seen. $\mathrm{OsO}_{4}$ fixation. Approximately $\times 8,600$. 


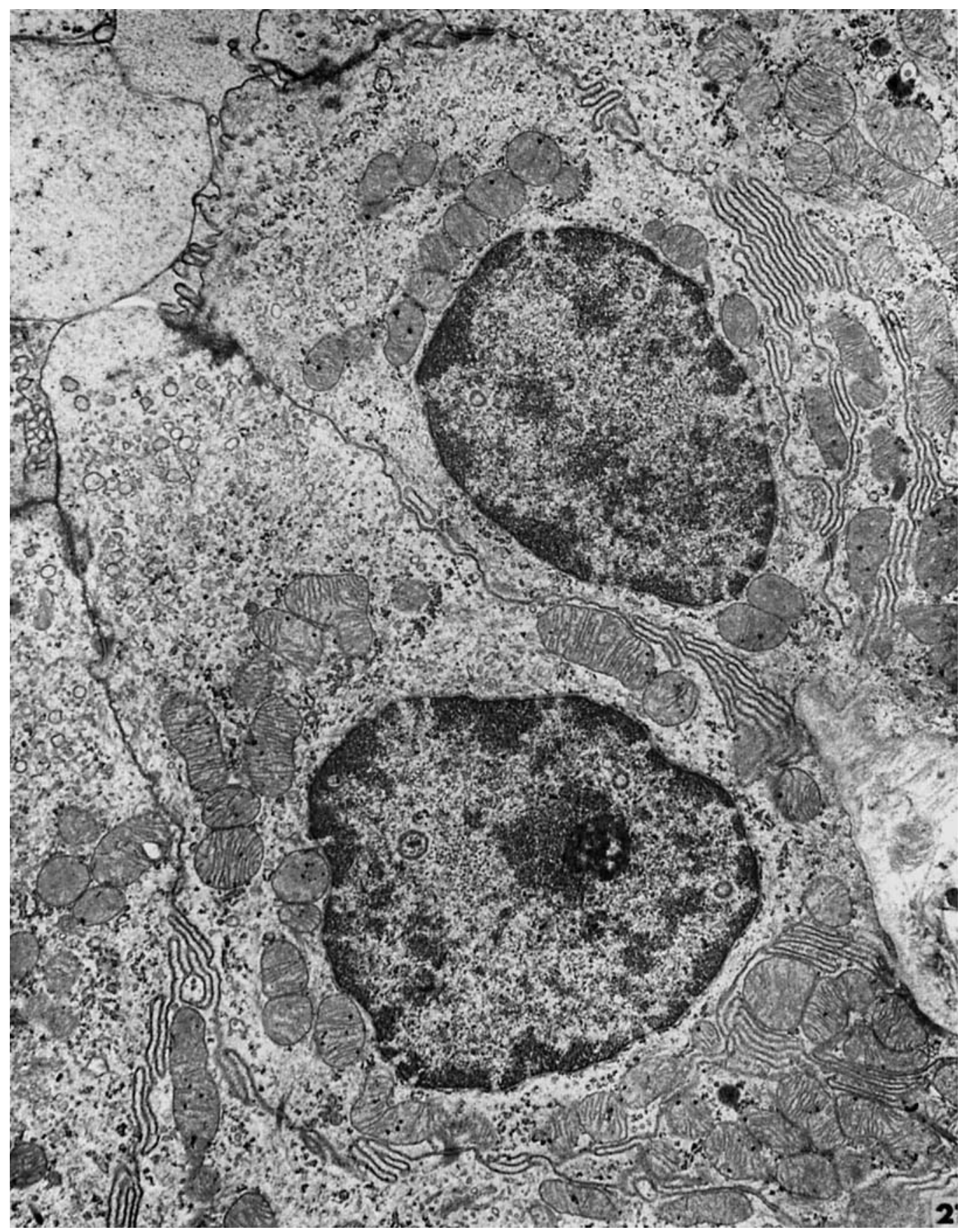




\section{PLATE 9}

EXPLANATION OF FIGURES

22 Portions of the apical cytoplasm of secretory duct cells from a control animal. Notice the small number of cytoplasmic vesicles or vacuoles in addition to the usual structure. $\mathrm{OsO}_{4}$ fixation. Approximately $\times 14,800$.

23 Portions of the apical cytoplasm of secretory duct cells from an experimental animal. Notice the increased number of apical vacuoles which also have gained electron density of their content. $\mathrm{OsO}_{4}$ fixation. Approximately $\times 14,800$. 


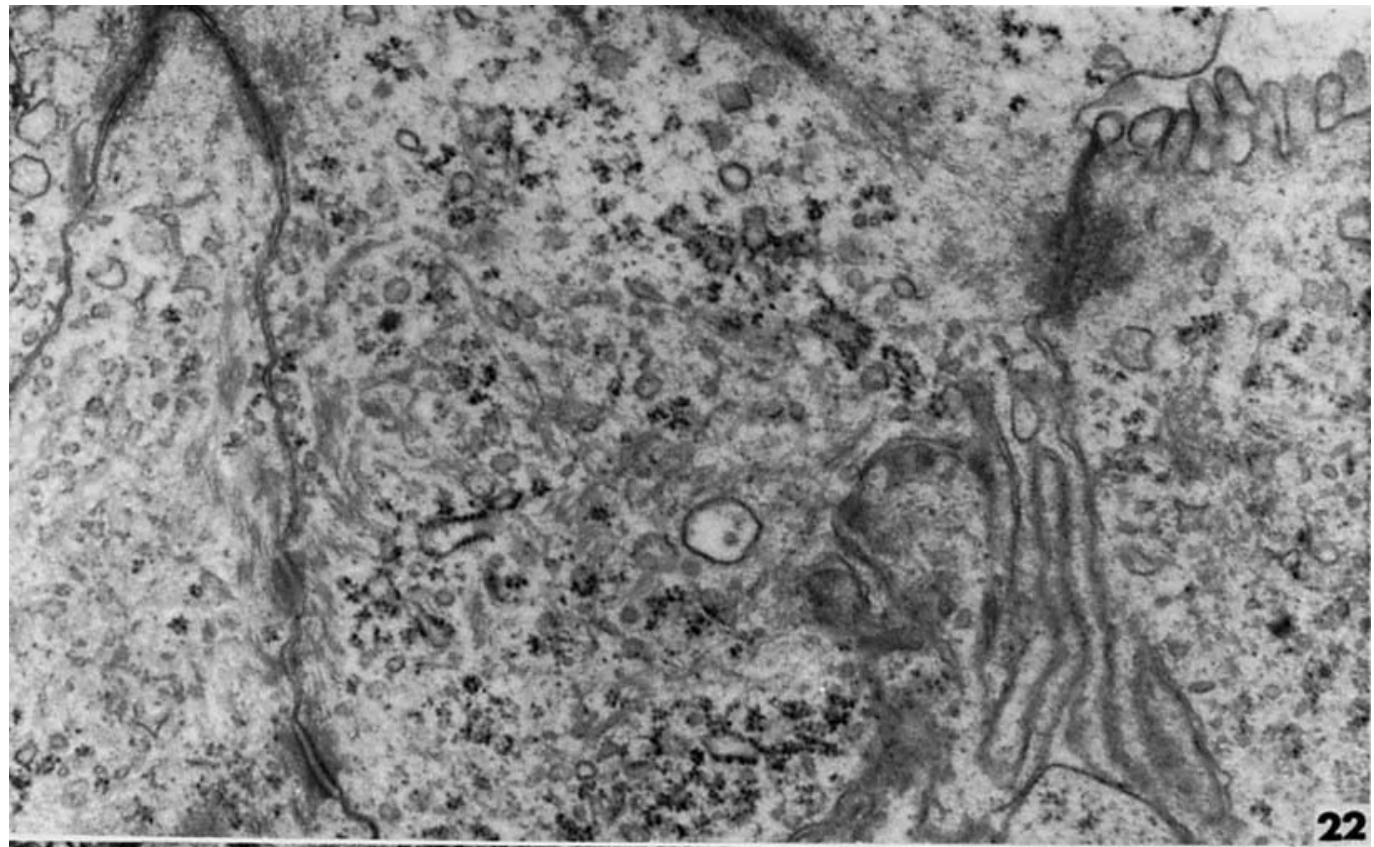

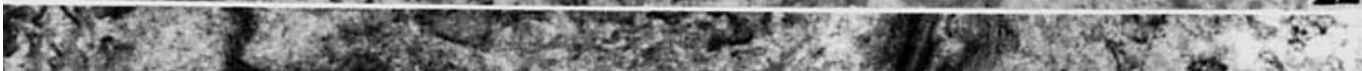

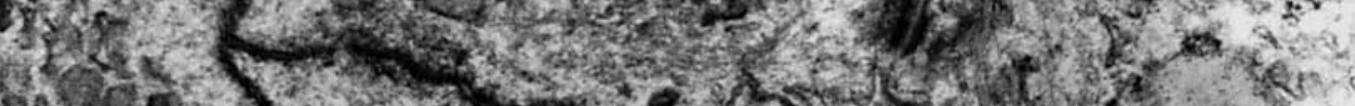

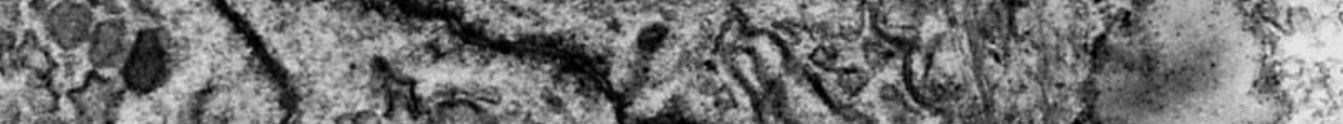

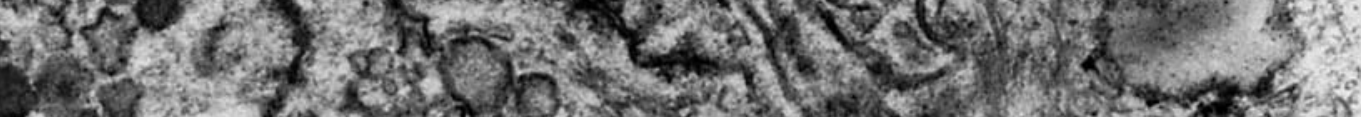

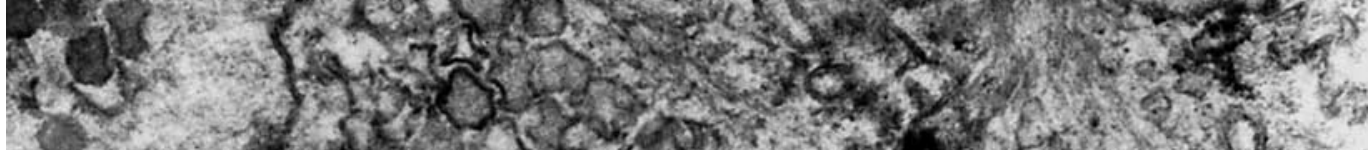

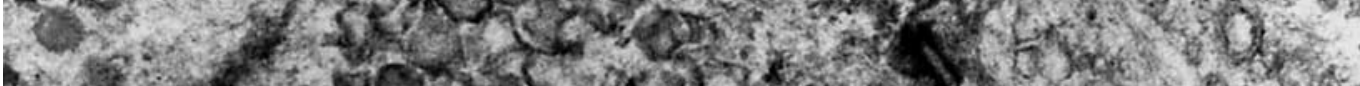

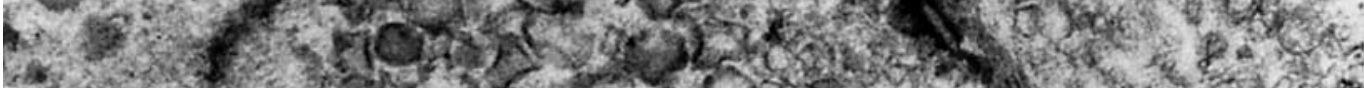

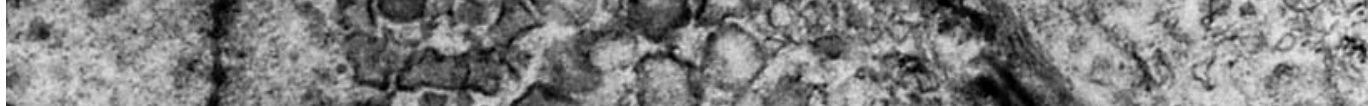

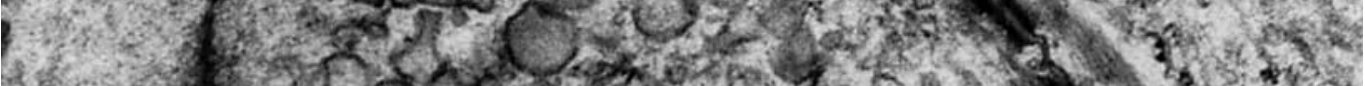

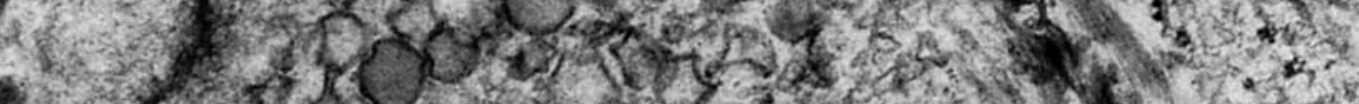

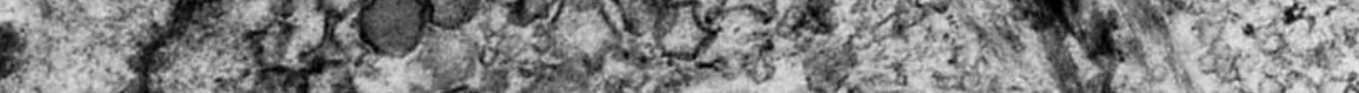

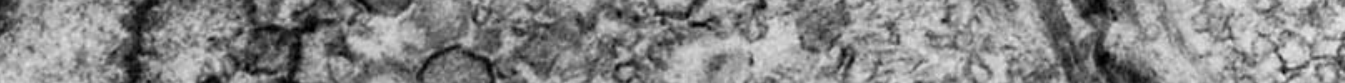

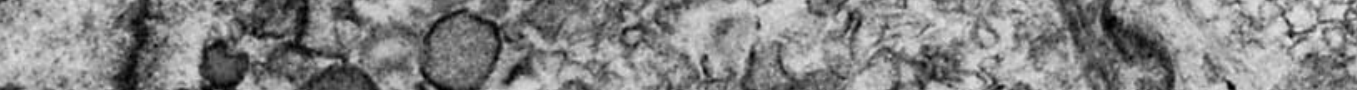

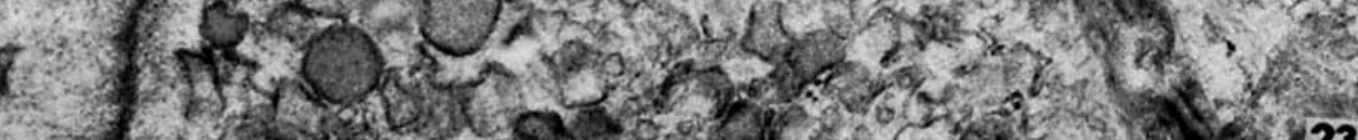

